\title{
APPLICATION OF VARIABLE VACUUM IN CARDIOSURGERY WITH COMPLICATIONS \\ Article history:
}

\author{
A.A. Furgal ${ }^{1,2}$ \\ ${ }^{1}$ Far Eastern Federal University, Vladivostok, \\ ${ }^{2}$ Pacific State Medical University, Vladivostok \\ e-mail:furgal86@bk.ru \\ This work was supported by Science Foundation Far Eastern Federal \\ University, in the framework of the state task from 17.5740/2017/6.7.
}

\section{RELEVANCE}

In the conditions of progress of modern medicine in the field of surgery, antibacterial therapy and preventive practices, postoperative sternomediastinal infections still remain a pressing public health problem. They have a significant impact on the survival rate, duration of hospitalization and the economic burden of treating cardiac patients. The problem of postoperative complications in cardiac surgery is very relevant at present, given the increase in the number of geriatric patients, patients with overweight and diabetes $[1,2]$.

Median sternotomy, as a surgical approach, has several disadvantages, one of which is the risk of developing infectious complications in the field of surgical intervention. They proceed with the formation of a superficial or deep wound infection, diastasis and fragmentation of the sternum, destabilization of the bone skeleton of the chest $[3,4,5]$.

The frequency of mediastinitis after cardiac surgery, as a rule, varies from $1 \%$ to $4 \%$ [3]. The failure of the stitches and the infection of the sternotomy wound is a terrible complication, with high mortality rates, which are in the risk group from 14 to $75 \%$ [6]. The development of PSM is associated with a significant decrease in long-term survival $[7,8]$. Risnes and colleagues showed that patients undergoing PSM have a $59 \%$ greater risk of death within a 10 -year period after surgery compared to patients who did not tolerate this complication. [9]. The authors attribute this to the fact that the chronic inflammatory process associated with mediastinitis can negatively affect the long-term patency of the shunts and thus lead to a decrease in survival [10].

The cost of treatment of patients with PSM is on average 2-3 times higher than the treatment of similar patients without this complication [1].
Received 21 January 2019

Received in revised form 29 January 2019

Accepted 20 February 2019

\section{PURPOSE OF THE STUDY}

Assess the effect of different vacuum drainage regimes and open reference methods on the healing of infected wounds and long-term results.

\section{MATERIAL AND METHODS}

Group 1 included patients using variable vacuum drainage, group 2 using continuous vacuum drainage, group 3 using the open reference method. Specialists involved in the analysis and interpretation of the histological component of the study were not provided with any information about the patients belonging to individual study groups, in order to reduce the likelihood of systematic statistical errors in the study and maximum objectification in the interpretation of histological data.

The study was conducted in accordance with the requirements of the Ministry of Healthcare of the Russian Federation No. 82 dated April 29, 1994 and according to the nomenclature of clinical laboratory research of the Ministry of Health of the Russian Federation (order No. 64 of February 21, 2000) taking into account the provisions of the Helsinki Declaration (2013). On the basis of prospective, controlled comparative studies, monitoring of morphological changes in the conditions of regeneration of an infected sternotomy wound was conducted in accordance with the principles of evidence-based medicine. Clinical and classical morphological research methods were used in monitoring reparative processes in patients with postoperative sternomediastinitis, followed by statistical analysis of the data obtained.

To solve questions about the possible mechanisms of reparative regeneration under the conditions of an open method of treatment, using constant and variable vacuum using morphological methods of research, we obtained an objective assessment of regeneration in damaged tissues. For a comparative assessment, tissue sampling for research was performed on the day of PSM detection and every 4 days after detection and initiation of PSM treatment, during the surgical rehabilitation of post-motone wounds, according to indications, in the volume of tissues not more than $1 \mathrm{~mm}^{3}$. 
Table 1. The distribution of patients by postoperative treatment methods

\begin{tabular}{l|l|l}
\hline Group number & Postoperative methods treatment & Number of patients \\
\hline 1 & Variable vacuum discharges & 13 \\
\hline 2 & Permanent vacuum discharges & 14 \\
\hline 3 & Open reference method & 30 \\
\hline Total: & 57 \\
\hline
\end{tabular}

\section{THE RESULTS OF THE STUDY}

In our studies, in all observation groups, in cuts made from biopsy samples of the wound surface area, CD differentiation cells CD68, CD163, CD34 were identified. Macrophages, which begin to migrate into the wound from the vessels together with granulocytes, have a more significant effect on the following stages of healing, but they reach the maximum level only by the $3 \mathrm{rd}$ day, decreasing after 6-7 days.

The physiological role and influence of macrophages are associated not only with their function of wound cleansing (by phagocytosis of erythrocytes, decaying leukocytes, fat cells and fibrin), but also with the secretion of specific substances that enhance fibroblast proliferation. Collagen fibers in any wounds are one of the main parts of wound detritus. They remain for a long time after the breakdown of the cells of the preexisting tissue, undergoing swelling, fibrillation, partial destruction and loss of fuchsinophilia. Collagen resorption is mainly a function of macrophages. However, they are not capable, like fibroblasts, to phagocytosis of collagen fibrils. The latter are subjected to fragmentation, destruction, granular disintegration and lysis in the immediate vicinity of macrophages, under the action of collagenolytic enzymes secreted by the cell, and then was phagocytosed. The most interesting are patients with type 2 diabetes mellitus, since they have active neovascularization in neuro-sensory structures and reduced angiogenesis and impaired trophism of tissues from other sites. Considering the role of the macrophage pool, which induces angiogenesis and participates in the phagocytosis of necrotic tissues, the effect on collagenogenesis in the healing process, we have obtained data on the localization and quantitative characteristics of cells expressing CD163.

In patients treated with variable vacuum drainage, identification of CD163 was detected in greater numbers than in patients in other observation groups.

In our studies, it was noted that the proliferative activity of structures in the zone of a regenerating postoperative wound correlates with the processes of angiogenesis and an increase in the number of macrophages. These indicators were dependent on the method of treatment and the most adequate ratios of indicators to successfully accelerate regeneration were observed in patients treated with variable vacuum drainage. We noted that in patients with diabetes, angiogenesis is compounded (less than CD163 and capillary density), less than endothelium growth factor, lower than CD34.

Analysis of the clinical manifestations in the postoperative period showed that the creation of negative pressure in the wound has a pronounced complex positive effect on the course of the disease: edema decreases, local blood circulation improves, bacterial load decreases, healing accelerates. Vacuum therapy improves throughout all stages of the wound process: reduces local edema, as a result - helps to enhance local blood circulation, reduces the level of microbial contamination of the wound, causes deformation of the wound bed and a decrease in the wound cavity, leading to accelerated wound healing. Also, vacuum therapy reduces the severity of wound exudation, helping to maintain a moist wound environment necessary for normal wound healing. All these effects contribute to an increase in the intensity of cell proliferation, enhance the synthesis in the wound of the main substance of connective tissue and proteins. The advantages of VAC therapy are that vacuum therapy by improving the quality of granulation tissue increases the chances of success in closing the wound with local tissues. The imposition of a vacuum-dressing on the wound allows you to remove excess wound exudate, stimulates angiogenesis.

The direct effect of vacuum on the wound bed leads to a local decrease in the partial pressure of oxygen in the wound; however, this, like in diabetes mellitus, stimulates the formation of new vessels and further improvement of the quality of granulation tissue in the wound. This ultimately results in increased tissue oxygenation, which is especially important for patients with concomitant CD.

\section{REFERENCES}

1. VishnevskiY A.A., Rudakov S.S., Milanov N.O. Khirurgiya grudnoi stenki. - M.: Vidar. 2005. P. 305.

2. Milano C.A., Kesler K., Archibald N., Sexton D.J., Jones R.H., Staci A.F. Mediastinitis after coronary artery bypass graft surgery. Risk factors and long-term survival. // Circulation. 1995. Vol. 92. P. 2245-2251.

3. Loop F.D., Lytle B.W., Cosgrove D.M., Mahfood S., McHenry M.C., Goormastic M., STewart R.W., Golding L.R., Taylor P.C. J. Maxwell Chamberlain memorial paper. Sternal wound complication after isolated coronary artery bypass grafting: early and late mortality, morbidity, and cost of care. // Ann. Thorac. Surg. 1990. Vol. 49. P. 179-186. 
4. EKLUND A.M., LYyTiKainen O., KLemets P., Huotari K., Anttila V.J., Werkkala K.A., VALTONEN M. Mediastinitis after more than 10,000 cardiac surgery procedures. // Ann. Thorac. Surg. 2006. Vol. 82. P. 1784-1789.

5. Crabtee T.D., Codd J.E., Fraser V.J., Bailey M.S., Olsen M.A., Damiano JR.R.J. Multivariate analysis of risk factors of deep and superficial sternal infection after coronary artery bypass grafting at a tertiary care medical center. // Semin. Thorac. Cardiovasc. Surg. 2004. Vol. 16-P. 53-61.

6. Braxton J.H., Marrin C.A., McGrath P.D., Ross C.S., Morton J.R., Norotsky M., Charlesworth D.C., Lahey S.J., Clough R.A., O'ConNor G.T. Mediastinitis and long-term survival after coronary artery bypass graft surgery. // Ann. Thorac. Surg. 2000. Vol. 70. P. 2004-2007.

7. SaChithanandan A., Nanjaiah P., NightinGale P., Wilson I.C., Graham T.R., RoONey S.J.,
Keogh B.E., Pagano D. Deep sternal wound infection requiring revision surgery: impact on mid-term survival following cardiac surgery. // Eur. J. Cardiothorac. Surg. 2008. Vol. 33. P. 673-678.

8. Risnes I., Abdelnoor M., Almdahl S.M., SvenNEVIG J.L. Mediastinitis after coronary artery bypass grafting risk factors and long-term survival. // Ann. Thorac. Surg. 2010. Vol. 89. P. 1502-1509.

9. Risnes I., Abdelnoor M., Ulimoen G., RyNNing S.E., Veel T., SVennevig J.L., Lundblad R., BORTHNE A. Mediastinitis after coronary artery bypass grafting increases the incidence of left internal mammary artery obstruction. // Int. Wound J. 2014. Vol. 11. P. 594-600.

10. Graf K., Ott E., Vonberg R.P., Kuehn C., Haverich A., Chaberny I.F. Economic aspects of deep sternal wound infections. // Eur. J. Cardiothorac. Surg. 2010. Vol. 37. P. 893-896. 